\title{
An Efficient and Simple Load Flow Approach for Radial and Meshed Distribution Networks
}

\author{
B. Ravi Teja ${ }^{1}$, V.V.S.N. Murty ${ }^{2}$, Ashwani Kumar, \\ member IEEE $^{3}$, Corresponding Author \\ 1, 2, 3 Department of Electrical Engineering, NIT Kurukshetra \\ ashwa_ks@yahoo.co.in,Tel:+911744233389
}

\begin{abstract}
The main contribution of this paper is: (i) proposing a new efficient and simple load flow method for balanced radial and meshed distribution systems, (ii) impact of load models, different $X / R$ ratios, load growth and tolerance levels to check robustness of proposed load flow method, (iii) impact of number of loops on meshed distribution systems, (iv) Comparison of radial and mesh distribution for voltage profile, total power losses, and number of iterations. The convergence ability of the proposed load flow method is evaluated under these conditions. Computer program has been developed to implement the power flow solution scheme in MATLAB and successfully applied to several practical distribution networks with radial and mesh structure. The convergence ability is quantitatively evaluated for different loading conditions, load growth, $R / X$ ratios, and tolerance levels. Moreover, the effects of static load modeling on the convergence characteristics of the proposed algorithm are also investigated. Effectiveness of the proposed load flow method has been tested on IEEE 33 bus and IEEE 69 bus radial and meshed distribution networks. The proposed load flow method is compared with existing load flow methods, Ghosh et al. [6], Aravindhababu et al. [7], and J.H.Teng [16] to demonstrate its effectiveness.
\end{abstract}

Keywords — Load flow, radial and mesh distribution system, load models, load growth

\section{List of Symbols}

$\begin{array}{ll}N & \text { Number of buses } \\ N b & \text { Number of branches } \\ L k & \text { Number of tie lines } \\ E & \text { Number of radial branches + No. of tie lines } \\ s e & \text { Sending end nodes } \\ r e & \text { Receiving end nodes } \\ A & \text { Bus incidence matrix } \\ B & \text { Basic cut set matrix } \\ C & \text { Basic loop incidence matrix } \\ I L[i] & \text { Load currents at each bus } \\ I B R[j] & \text { Currents in branch } \mathrm{j} \\ Z p u & \text { Per Unit Impedance for all branches } \\ V(j) & \text { Voltage at node } \mathrm{j} \\ \text { delV } & \text { Voltage deviation in successive iterations } \\ T P L & \text { Total real power loss } \\ T Q L & \text { Total reactive power loss } \\ \text { Ploss }(k) & \text { Real power loss for branch } \mathrm{k} \\ \text { Qloss }(k) & \text { Reactive power loss for branch } \mathrm{k}\end{array}$




$\begin{array}{ll}r & \text { Annual rate growth } \\ m & \text { Plan period up to which feeder can take the load }\end{array}$

\section{Introduction}

Distribution system power flow study is the backbone for distribution automation. Therefore, an accurate, robust, and computationally efficient distribution power flow tool is highly demanded. Load flow is an important and fundamental tool for the analysis of any power system in operation as well as planning stages, particularly in modern distribution system and optimization of power system. The well-known characteristics of an electric distribution system are radial and meshed structures; multiphase and unbalanced operation; unbalanced distributed load; extremely large number of branches and nodes; wide ranging resistance and reactance values. Those features cause the traditional power flow methods used in transmission systems, such as the Gauss-Seidel and Newton-Raphson techniques, to fail to meet the requirements in both performance and robustness aspects in the distribution system applications [1].

A power flow method must be robust and time efficient to tackle the special features of distribution system. The optimal distribution system planning is very important for the growth of distribution system network and plays an important role for effective usage of the distribution system. With the continuing increase in load demand, the future expansion of the network depends on the load flow study of the distribution system network and thus is one of the most important research fields for electrical engineering. With the growing effort to reduce system losses, increase in the efficiency of the system, and proper voltage profile, many papers refer to optimal distribution system planning [2]. The methods which are adopted for the analysis of radial distribution systems are based on the concept of the backward/forward method [4-8].

The methods [9-20] are adopted for the analysis of weakly meshed distribution systems are based on the concept of break point power injection and bus current injection. Shirmohammadi et al. [9] have presented a compensation based power flow method for radial distribution networks and/or for weakly meshed structure using a multi-port compensation technique and basic formulations of Kirchhoff's Laws. The radial part is solved by a straightforward two-step procedure in which the branch currents are first computed (backward sweep) and then bus voltages are updated (forward sweep). Luo and Semlyen [10] used active and reactive powers flow, a tree labeling technique and a solution strategy, to reducing the burden of mismatch calculations. The main disadvantage of this method is that the branch and node numbering scheme and data preparation are highly involved. Another difficulty of their method is that if new branch is inserted, numbering of branch of that part of network is necessary. Haque [11] proposed for the analysis of both radial and mesh networks.

A mesh network is converted to a radial network by breaking the loops through adding some dummy buses. The power injections at the loop break points (LBP) in the equivalent radial network are computed through a reduced order node impedance matrix. Unlike other methods, the shunt admittances are considered in the proposed load flow algorithm and the effect of load admittances is also incorporated in the calculation of power injections at the LBPs. Losi and Russo [12] presented an Object oriented load flow modeling for both radial and weakly meshed distribution system. The algorithm is based on the Newton Raphson technique. Some approximations to the full Jacobian matrix are introduced and sufficient conditions for convergence are derived. Sivanagaraju, et al. [13] described a distinctive load flow solution technique for weakly meshed distribution systems using branch injection branch current matrix which is obtain by applying Kirchhoff's current law. Bus voltages are found by forward sweep of the network. D. Rajieic, et al. [14] presented the admittance summation method and represented node loads by corresponding admittances. In the backward sweep, for each node we calculate 
the driving point admittance of the part of the network fed by the node, including the load at the node. In the forward sweep, we use these driving point admittances to calculate the node voltages. Gary Chang, et al. [15] proposes an efficient backward-forward sweep algorithm for three phase power flow analysis of weakly meshed distribution system. In the backward sweep KCL is used to calculate each line current and upstream bus voltages. Then linear proportional principle is applied to find the ratios of the specified and calculated bus voltages of the decomposed real and imaginary parts of the network. Compensation method is applied to break meshes and to calculate the current injections at each bus created by breaking the mesh.

Jen-Hao Teng [16] introduces two developed matrices; the bus-injection to branchcurrent matrix and the branch-current to bus-voltage matrix, and a simple matrix multiplication are utilized to obtain load flow solutions. P. R. Bijwe, et al. [17] proposed fuzzy logic based distribution power flow for weakly meshed balanced and unbalanced distribution systems. Dharmasa, et al. [18] presented a load flow method for radial and weakly meshed networks based on the collection of graphical information and application of concept of duality to the distribution network. W.M.Lin, et al. [19] a phase decoupled load flow method is proposed for distribution networks with radial or weakly meshed structures. G.J.Chen, et al. [20] presented two stage method for analysis of weakly meshed network. In the first stage, a meshed network is converted to a radial network by breaking the loops. The load flow of this radial network is calculated by applying the forward backward sweep method. In the second stage, injection currents of breakpoints are modified and the load flow of the radial network is calculated again, which is just the load flow of the original meshed network. Literature survey as mentioned above shows that very less work has done on solving weakly meshed distribution networks. An efficient load flow method is proposed in this paper which can deal with both radial and meshed distribution networks, is essential and very important for planning studies.

The proposed load flow approach does not require, formation of BIBC and BCBV matrices [16], tree labeling $[9,10]$, breaking the loops and injecting power injections $[9,10,11]$. In this paper a common load flow method is developed based on network topology and basic circuit theory concepts which can deal with both radial and mesh distribution networks efficiently. The convergence characteristic of the proposed method is illustrated and two IEEE benchmark distribution systems are extensively tested with various operating conditions. Results tested on the benchmark systems with meshes show that the proposed algorithm is accurate, robust, and computationally efficient. The entire analysis has been carried out for both radial and mesh distribution systems. In this paper results has been given for IEEE 33 and 69 bus mesh networks. Impact of all load models has been considered for the analysis of meshed distribution network. The line and load data for 33 bus and 69 bus systems are taken from [22] and [23] respectively. The analysis has been carried developing codes in MATLAB 7.0.4 [24].

\section{Mathematical Model for Radial Distribution Systems}

Radial distribution systems have poorest service reliability. In radial distribution systems customers at far end of the substation suffers from major voltage drops and distributor near to substation gets heavily loaded. To improve reliability and provide better voltage regulation meshed distribution networks are used by closing the tie line switches. Some distribution feeders serving high density load areas contain loops created by closing tie line switches.

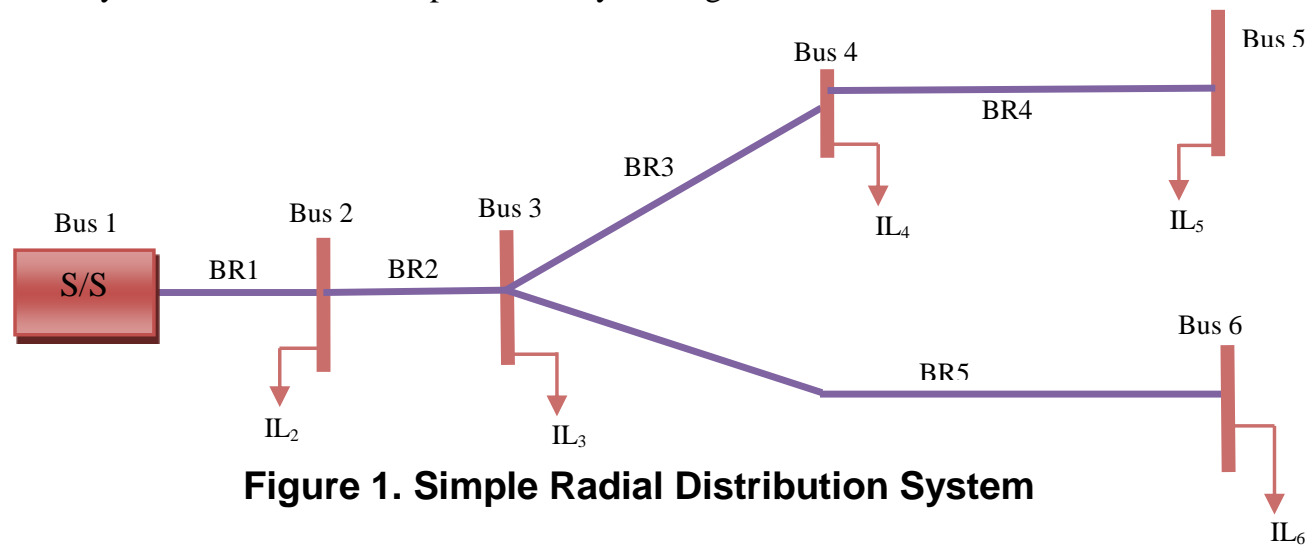


The branch currents can be calculated by knowing load currents as obtained from eqn. (19). For example, the branch currents of six bus radial network as shown in Figure 1 $I B R 1, I B R 2, I B R 3, I B R 4$ and $I B R 5$ can be expressed by equivalent current injections as

$$
\begin{aligned}
& I B R 1=I L_{2}+I L_{3}+I L_{4}+I L_{5}+I L_{6} \\
& I B R 2=I L_{3}+I L_{4}+I L_{5}+I L_{6} \\
& I B R 3=I L_{4}+I L_{5} \\
& I B R 4=I L_{5} \\
& I B R 5=I L_{6}
\end{aligned}
$$

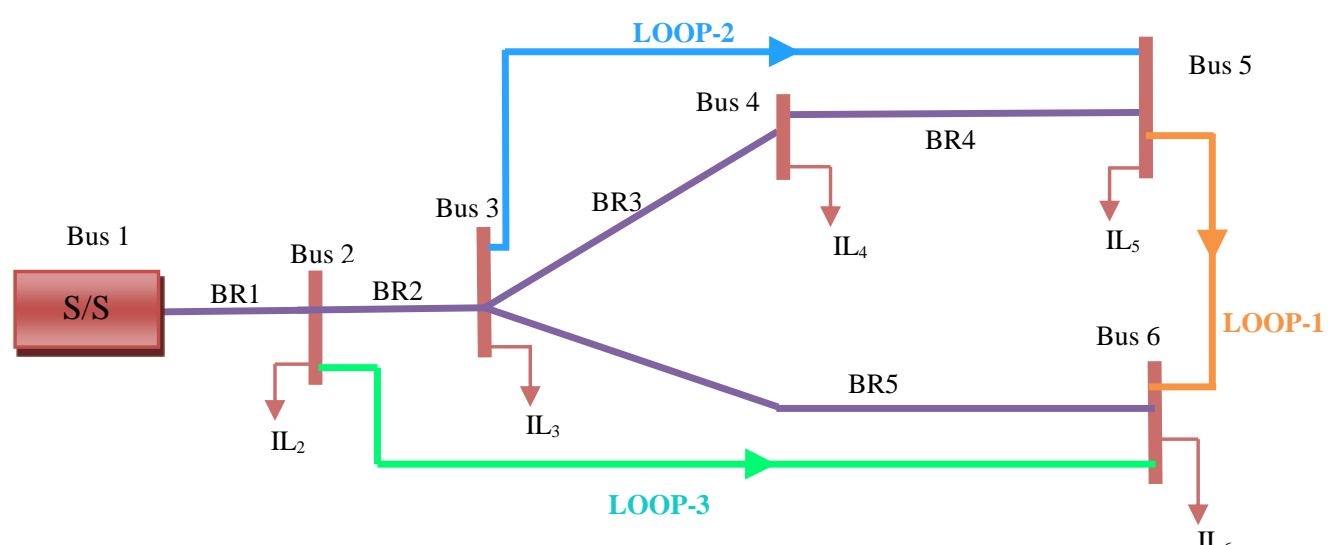

Figure 2. Simple Meshed Distribution System with Three Loops

The simple distribution system with three loops addition to make the network as a mesh network is shown in Figure 2. The mathematical modeling for load flow analysis of meshed distribution network is explained in detail as below. In the presence of tie lines the currents are recalculated as:

$$
\begin{aligned}
& I B R 1^{\prime}=I B R 1 \\
& I B R 2^{\prime}=I B R 2-I_{\text {loop }}(3) \\
& I B R 3^{\prime}=I B R 3+I_{\text {loop }}(1)-I_{\text {loop }}(2) \\
& I B R 4^{\prime}=I B R 4+I_{\text {loop }}(1)-I_{\text {loop }}(2) \\
& I B R 5^{\prime}=I B R 5-I_{\text {loop }}(1)-I_{\text {loop }}(3)
\end{aligned}
$$

Apply KVL in each loop:

For loop1:

$Z_{34} * I B R 3^{\prime}+Z_{45} * I B R 4^{\prime}-Z_{36} * I B R 5^{\prime}+Z_{56} * I_{\text {loop }}(1)=0$

$Z_{34} *\left(I B R 3+I_{\text {loop }}(1)-I_{\text {loop }}(2)\right)+Z_{45} *\left(I B R 4+I_{\text {loop }}(1)-I_{\text {loop }}(2)\right)-Z_{36} *(I B R 5-$

$\left.I_{\text {loop }}(1)-I_{\text {loop }}(3)\right)+Z_{56} * I_{\text {loop }}(1)=0$

$\left(\left(Z_{34}+Z_{45}+Z_{36}+Z_{56}\right) * I_{\text {loop }}(1)\right)-\left(\left(Z_{34}+Z_{45}\right) * I_{\text {loop }}(2)\right)+Z_{36} * I_{\text {loop }}(3)=$ $-\left(Z_{34} * I B R 3+Z_{45} * I B R 4-Z_{36} * I B R 5\right)$

For loop 2:

$-\left(\left(Z_{34}+Z_{45}\right) * I_{\text {loop }}(1)\right)-\left(\left(Z_{34}+Z_{45}+Z_{35}\right) * I_{\text {loop }}(2)\right)=-\left(-Z_{34} * I B R 3-Z_{45} * I B R 4\right)$

For loop 3:

$\left(Z_{36} * I_{\text {loop }}(1)\right)+\left(\left(Z_{23}+Z_{36}+Z_{26}\right) * I_{\text {loop }}(3)\right)=-\left(-Z_{23} * I B R 2-Z_{36} * I B R 5\right)$ 
Eqns. (5-7) can be represented in matrix form as:

$$
\begin{aligned}
& {\left[\begin{array}{ccc}
\left(Z_{34}+Z_{45}+Z_{36}+Z_{56}\right) & -\left(Z_{34}+Z_{45}\right) & Z_{36} \\
-\left(Z_{34}+Z_{45}\right) & \left(Z_{34}+Z_{45}+Z_{35}\right) & 0 \\
Z_{36} & 0 & \left(Z_{23}+Z_{36}+Z_{26}\right)
\end{array}\right]\left[\begin{array}{c}
I_{\text {loop }}(1) \\
I_{\text {loop }}(2) \\
I_{\text {loop }}(3)
\end{array}\right]=} \\
& -\left[\begin{array}{c}
\left(Z_{34} * I B R 3+Z_{45} * I B R 4-Z_{36} * I B R 5\right) \\
\left(-Z_{34} * I B R 3-Z_{45} * I B R 4\right) \\
\left(-Z_{23} * I B R 2-Z_{36} * I B R 5\right)
\end{array}\right]
\end{aligned}
$$

$[$ Zloop $] * I_{\text {loop }}=-[$ VDloop $]$

The currents in each loop can be determined as:

$I_{\text {loop }}=[\text { Zloop }]^{-1} *[-$ VDloop $]$

Let us consider

$A$ is the bus incidence matrix [21]

$\mathrm{B}$ is the basic cut set matrix [21]

$C$ is the basic loop incidence matrix [21]

$I B R$ is the vector of branch currents

$I L$ is the vector of load currents

$v$ is the vector of previous iteration bus voltages

$V$ is the vector of present iteration bus voltages

$P L, Q L$ are the real and reactive power load demand

$A=\left[\begin{array}{c}\mathrm{Ab} \\ \mathrm{Al}\end{array}\right]$

$B_{l}=A_{l} *\left(A_{b}{ }^{-1}\right)$

$C_{b}=-B_{l}{ }^{\prime}$

$C_{l}=\operatorname{eye}(L k, L k)$

$C=\left[C_{b} ; C_{l}\right]$

1. Calculation of Loop Impedance Matrix(Zloop)

Size of Zloop $=($ No. of links $\times$ No. of links $)$

Diagonal elements of loop impedance matrix

$Z l o o p(i, i)=Z \operatorname{loop}(i, i)+a b s(C(j, i)) * Z p u(j)$

$$
\text { for } i=1: L k \text { and for } j=1: E
$$

Off diagonal elements of loop impedance matrix

$$
\begin{aligned}
& Z \operatorname{loop}(i, j)=Z \operatorname{loop}(i, j)+C(k, i) * C(k, j) * Z p u(k) \\
& \quad \operatorname{loop}(j, i)=Z \operatorname{loop}(i, j) \\
& \quad \text { for } i=1: L k, \text { for } j=i+1: L k \text { and for } k=1: N b
\end{aligned}
$$

2. Load Currents Calculation

$$
\begin{gathered}
I L[i]=\left[\frac{P L(i)+j \cdot Q L(i)}{v(i)}\right]^{*} \\
\text { for } i=1,2,3, \ldots . N
\end{gathered}
$$

3. Backward Sweep to Sum up Line Section Current: Starting from the last branch and moving towards the root node, the current in branch $I B R$ is:

$I L(\operatorname{se}(k))=I L(r e(k))+I L(\operatorname{se}(k))$

$\operatorname{IBR}(k)=I L(r e(k))$

for $k=N b, N b-1, N b-2, \ldots, 3,2,1$

$\operatorname{VDloop}(i)=\operatorname{VDloop}(i)+C(j, i) * Z p u(j) * I B R(j)$

$$
\text { for } i=1: L k \text { and for } j=1: N b
$$

5. Calculate the Currents in each Loop

$$
I_{\text {loop }}=\left(\text { Zloop }^{-1}\right) *(-V \text { Dloop })
$$


6. Modify the Branch Currents

$\operatorname{IBR}(i)=\operatorname{IBR}(i)+C(i, j) * I_{\text {loop }}(j)$ for $i=1: n b$ and for $j=1: L k$

7. The Voltages at the Receiving end Node $\mathrm{k}$

$V(r e(k))=V(s e(k))-Z p u(k) * I B R(k) \quad$ for $k=1: N b$

7.1 Voltage Deviations in Present and Previous Iterations

$$
\text { delV }=V-v
$$

7.2 Convergence Criterion

$$
\operatorname{del} V_{\text {max }}=(\max (\operatorname{del} V))
$$

7.3 Updating Voltages

$$
v=V
$$

Knowing branch currents, the real and reactive power losses can be obtained as:

$\operatorname{Ploss}(k)=I B R^{2}(k) \times R p u(k)$ for $k=1,2,3, \ldots E$

$\operatorname{Qloss}(k)=I B R^{2}(k) \times X p u(k)$ for $k=1,2,3, \ldots E$

\subsection{Algorithm for Proposed Load Flow Solution of Meshed Distribution System}

Step 1: Read bus data and line data.

Step 2: Initialize the bus voltages asv $(\mathrm{i})=1.0$.

Step 3: Built the Basic loop incidence matrix (C).

Step 4: Calculate the loop impedance matrix using eqns. (16-18).

Step 5: Calculate load currents IL using eqn. (19).

Step 6: Calculate branch currents in radial network using eqns. (20-21).

Step 7: Calculate the voltage drops in each loop using eqn. (22).

Step 8: Calculate the currents in each loop using eqn. (23).

Step 9: Modify the final branch currents with loop currents calculated in step 8 using eqn. (24).

Step 10: Calculate voltages in the forward direction using eqn. (25).

Step 11: Find delV using eqn. (26). Update the voltages as shown in eqn. (27).

Step 12: Find error in voltage i.e. delV $V_{\max }$. If it is less than 0.0001 then load flow is converged otherwise go to step 5.

Step 13: Once load flow is converged bus voltages and branch currents are known then find power losses using eqns. (28-29).

Step 14: Stop. The proposed load flow method for meshed distribution system can easily applied to radial distribution systems by ignoring the steps $3,4,7,8$ and 9 in the above algorithm. In case of radial network number of tie lines is zero, so number of elements is equals to number of branches. Also the treatment for load flow of radial distribution system is explained briefly as below.

\subsection{Algorithm for Proposed Load Flow Solution of Radial Distribution System}

Step 1: Read bus data and line data.

Step 2: Initialize the bus voltages as $\mathrm{v}(\mathrm{i})=1.0$

Step 3: Calculate load currents IL using eqn. (19).

Step 4: Calculate branch currents using eqn. (20-21).

Step 5: After calculating voltage drops find receiving end voltages in the forward direction using eqn. (25)

Step 6: Find delV using eqns. (26). Update the voltages as shown in eqn. (27).

Step 7: Find error in voltage i.e. $\operatorname{delV}_{\max }$. If it is less than 0.0001 then load flow is converged otherwise go to step 3.

Step 8: Once load flow is converged bus voltages and branch currents are known then find power loss using eqns. (28-29)

Step 9: Stop 


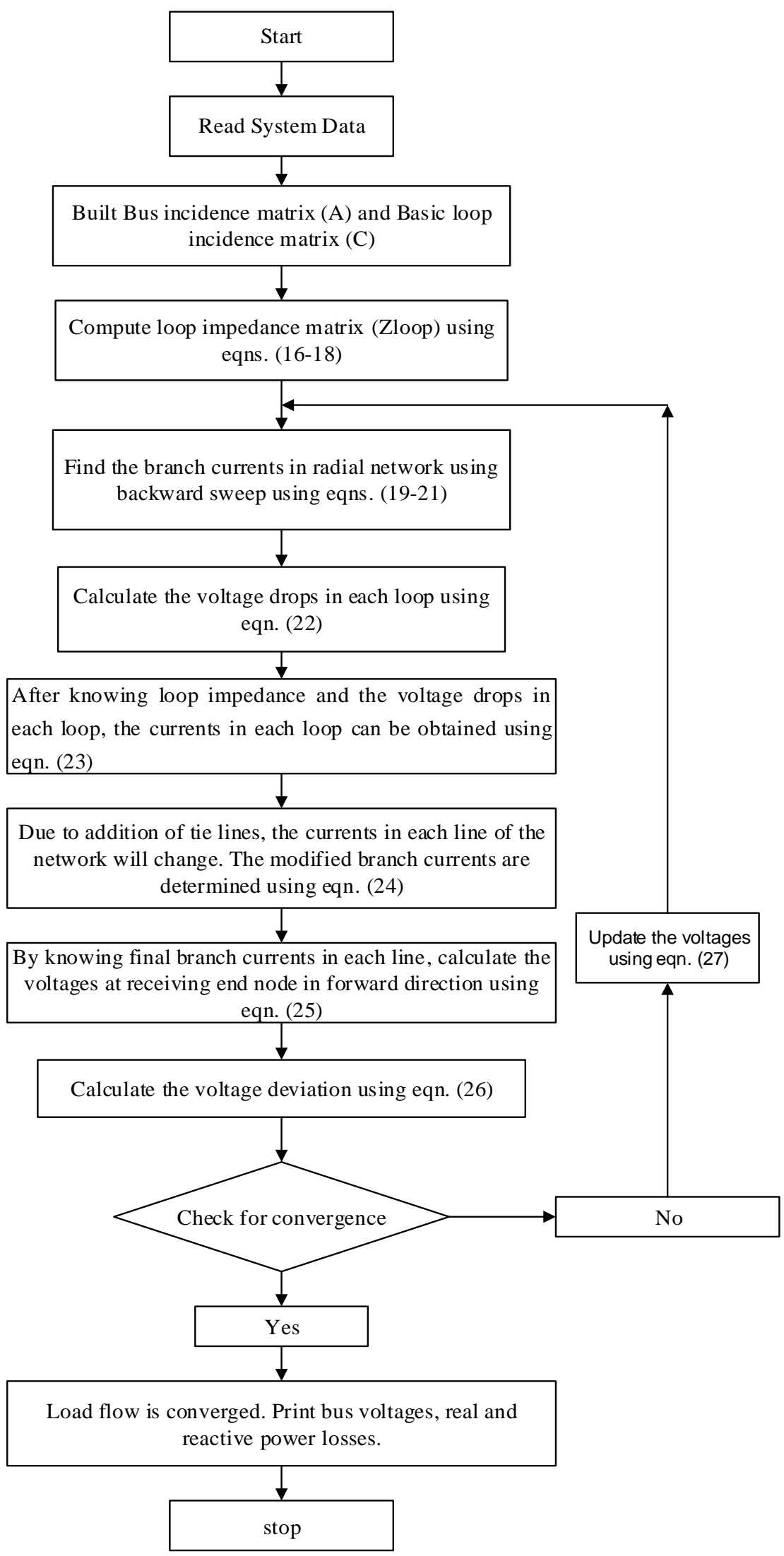
Figure 3. Flow Chart of the Proposed Load Flow Technique for
Meshed Distribution System 


\section{Model of Load Growth}

For future expansion and planning of the distribution systems, it is desirable that a system engineer must know the future estimate of the system solutions for planning and expansion or the efficient operation of distribution systems. The load growth (LG) pattern is essential to know for future planning and expansion of the distribution systems. In this paper work, load growth is modeled as:

$\operatorname{Load}_{i}=\operatorname{Load} \times(1+\mathrm{r})^{\mathrm{m}}$

$\mathrm{r}=$ annual growth rate

$\mathrm{m}=$ plan period up to which feeder can take the load

In this paper work $\mathrm{r}=0.07$ and $\mathrm{m}=5$. The load growth is incorporated for all the systems to consider the impact of load growth on voltage profile, total real and reactive power losses, number of iterations and convergence time.

\subsection{Static Load Models}

In conventional load flow studies, it is presumed that active and reactive power demands are specified constant values, regardless of the amplitude of voltages in the same bus. In actual power systems operation, different categories and types of loads such as residential, industrial, and commercial loads are present. The nature of these types of loads is such that their active and reactive powers are dependent on the voltage and frequency of the system. Moreover, load characteristics have significant effects on load flow solutions and convergence ability. Common static load models for active and reactive power are expressed in a polynomial or an exponential form. The characteristic of the exponential load models can be given as:

$$
\begin{aligned}
& P=P_{o}\left(\frac{V}{V_{o}}\right)^{n_{p}} \\
& Q=Q_{o}\left(\frac{V}{V_{o}}\right)^{n_{q}}
\end{aligned}
$$

Where, $n_{p}$ and $n_{q}$ stand for load exponents, $P_{o}$ and $Q_{o}$ stand for the values of the active and reactive powers at the nominal voltages. $V$ and $V_{o}$ stand for load bus voltage and load nominal voltage, respectively.

Table 1. Exponents for Different Static Load Models [8]

\begin{tabular}{|c|c|c|}
\hline Load component & $\boldsymbol{n}_{\boldsymbol{p}}$ & $\boldsymbol{n}_{\boldsymbol{q}}$ \\
\hline Battery charge & 2.59 & 4.06 \\
\hline Fluorescent lamps & 2.07 & 3.21 \\
\hline Constant power & 0 & 0 \\
\hline Constant impedance & 2 & 2 \\
\hline Fluorescent lighting & 1 & 3 \\
\hline Air conditioner & 0.5 & 2.5 \\
\hline Constant current & 1 & 1 \\
\hline Resistance space heater & 2 & 0 \\
\hline Pumps, funs other motors & 0.08 & 0 \\
\hline Incandescent lamps & 1.54 & 0.35 \\
\hline Compact fluorescent lamps & 1 & 0.6 \\
\hline Small industrial motors & 0.1 & 0.5 \\
\hline Large industrial motors & 0.05 & 6.00 \\
\hline Industrial & 0.18 & 4.04 \\
\hline Residential & 0.92 & 3.40 \\
\hline Commercial & 1.51 & \\
\hline
\end{tabular}




\subsection{Polynomial Load Model}

In this paper, a realistic static load model is considered that represents the powervoltage relationship as a polynomial equation of voltage magnitude. It is usually referred to as the ZIP model, as it is made up of three different load models: constant impedance $(\mathrm{Z})$, constant current (I) and constant power (P). The real and reactive power characteristics of ZIP load model are given as:

$P=P_{o}\left[a_{p}\left(\frac{V}{V_{o}}\right)^{2}+b_{p}\left(\frac{V}{V_{o}}\right)+c_{p}\right]$

$Q=Q_{o}\left[a_{q}\left(\frac{V}{V_{o}}\right)^{2}+b_{q}\left(\frac{V}{V_{o}}\right)+c_{q}\right]$

Where, the sum of the ZIP load coefficients for both P, and Q loads is equal to 1 .

$a_{p}+b_{p}+c_{p}=1, a_{q}+b_{q}+c_{q}=1$

In this paper work $a_{p}=a_{q}=0.3, b_{p}=b_{q}=0.2, c_{p}=c_{q}=0.5$

$\mathrm{P}_{\mathrm{o}}$ and $\mathrm{Q}_{\mathrm{o}}$ are the real and reactive power consumed at a reference voltage $\mathrm{V}_{\mathrm{o}}$.

\section{Results and Discussions}

The proposed power flow algorithm is implemented using MATLAB Version 7.0.4 and tested on Windows 7, Intel Xeon Core, $3.40 \mathrm{GHz}, 4 \mathrm{~GB} R A M$. The results have been obtained for two IEEE 33 [22] and 69 bus [23] test systems considering load growth, different load models and different R/X ratios. The results show that the proposed load flow method is in close agreement with already existing methods. The popular voltage dependent load models and load growth have been considered to study the impact on convergence ability. The effect of the loops has also been incorporated to observe the impact on the system performance. The results for radial and meshed distribution systems have also been obtained for comparison. For meshed distribution networks the number of iterations was lower than radial networks, due to improvement in voltage profile in meshed networks with loops.

The voltage profile for IEEE 33 and 69 bus meshed systems with CP load model considering different number of loops are given in Tables 2-3. The results obtained with other methods are also given in the tables for comparison. The results obtained with the proposed method and reported in $[6,7,16]$ are in close agreement. It is observed from the Tables 2-3 that the voltage profile improves with increase in loops due to the reduction in the kVA requirement from the substation and thereby the reduction in the real and reactive power losses for both 33 and 69 bus meshed systems. With consideration of five loops, the voltage profile is better for all types of static load models. The comparison of voltage profile, total power losses and number of iterations for both radial and meshed distribution networks are given in Tables 2-3 for both the test systems. From Table 2-3 we can observe that with increase of number of loops the number of iterations is slightly reducing because of improved voltage profile with the loops. For meshed distribution network, voltage profile, total power losses, number of iterations and convergence time with CP, CI, CZ, ZIP load models, impact of load growth and increase in R and X on CP load model are given in Tables 4-5 for 33 and 69 bus meshed distribution networks respectively. Tables 4-5 it can be observed that CP load model is converging in less time than CI, CZ and ZIP load models. Also with increase of R, X and in the presence of load growth converging time is increasing for $\mathrm{CP}$ load model. The impact of loading on meshed distribution systems is given in Table 6 in terms of total power losses, minimum voltage and number of iterations.

The convergence characteristic of the proposed method is analyzed for different $\mathrm{R} / \mathrm{X}$ ratios, loading conditions, load growth, tolerance values, and different static load models on 33 and 69-bus meshed distribution networks. Different loading conditions are considered by multiplying each node's power by a load factor (lf) as $P L=P L o *$ 
lf, $Q L=Q L o * l f$, and results are depicted in Figure 4 for the variation of $l f$ from 0.5 to 3. $\mathrm{R} / \mathrm{X}$ ratio of branch impedances are varied by multiplying each branch resistance by a coefficient $(k)$ as $R=R o * k, X=X o * k$, and results are depicted in Figure.5-6 for the variation of $\mathrm{k}$ from 1 to 3 respectively. Impact of all static voltage dependent load models on number of iterations is shown in Figure 7. Battery charge and industrial load models are converging in high number of iterations, whereas constant current load model is converging in less number of iterations as shown in Figure 7.

Convergence tolerances for the proposed method have been checked for values as $10^{-4}, 10^{-5}, 10^{-6}, 10^{-7}, 10^{-8}, 10^{-9}$, and $10^{-10}$ and results depicted in Figure 8. From Figure 8 , it can be observed that with increase in tolerance level, the number of iterations to converge the load flow solution increases for both the test systems.

Table 2. Voltage profile (p.u.) for IEEE 33 Bus Distribution system

\begin{tabular}{|c|c|c|c|c|c|c|c|c|}
\hline \multicolumn{9}{|c|}{ CP Load model (epsilon=0.0001) } \\
\hline Bus & \multicolumn{2}{|c|}{ Radial } & Loops-1 & Loops-2 & Loops-3 & Loops-4 & \multicolumn{2}{|c|}{ Loops-5 } \\
\hline & $\begin{array}{c}\text { Proposed } \\
\text { V (p.u) }\end{array}$ & $\begin{array}{c}\text { Ref [6, } 7 \\
\text { and 16] } \\
\text { V(p.u) }\end{array}$ & \multicolumn{5}{|c|}{ Proposed V(p.u) } & $\begin{array}{c}\text { Ref [16] } \\
\text { V (p.u) }\end{array}$ \\
\hline 1 & 1 & 1 & 1 & 1 & 1 & 1 & 1 & 1 \\
\hline 2 & 0.997025 & 0.997025 & 0.997064 & 0.997069 & 0.997077 & 0.997081 & 0.997092 & 0.997092 \\
\hline 3 & 0.982893 & 0.982893 & 0.986086 & 0.986103 & 0.986542 & 0.986777 & 0.986332 & 0.986332 \\
\hline 4 & 0.975384 & 0.975384 & 0.980906 & 0.980933 & 0.98169 & 0.982096 & 0.982711 & 0.982711 \\
\hline 5 & 0.967958 & 0.967958 & 0.975903 & 0.97594 & 0.977028 & 0.977611 & 0.979329 & 0.979329 \\
\hline 6 & 0.949481 & 0.949481 & 0.963692 & 0.963755 & 0.965676 & 0.966795 & 0.971425 & 0.971425 \\
\hline 7 & 0.945956 & 0.945956 & 0.963187 & 0.96326 & 0.965553 & 0.965933 & 0.970504 & 0.970504 \\
\hline 8 & 0.932301 & 0.932301 & 0.961378 & 0.961499 & 0.965382 & 0.963861 & 0.96825 & 0.96825 \\
\hline 9 & 0.925969 & 0.925969 & 0.955245 & 0.955422 & 0.962909 & 0.960171 & 0.965091 & 0.965091 \\
\hline 10 & 0.920095 & 0.920095 & 0.949557 & 0.952552 & 0.962845 & 0.959868 & 0.964721 & 0.964721 \\
\hline 11 & 0.919226 & 0.919226 & 0.948716 & 0.952163 & 0.962897 & 0.959887 & 0.964732 & 0.964732 \\
\hline 12 & 0.917712 & 0.917712 & 0.94725 & 0.951559 & 0.963128 & 0.960058 & 0.964886 & 0.964886 \\
\hline 13 & 0.911536 & 0.911536 & 0.941271 & 0.949652 & 0.960064 & 0.955929 & 0.961521 & 0.961521 \\
\hline 14 & 0.909246 & 0.909246 & 0.939054 & 0.949229 & 0.95908 & 0.954364 & 0.960327 & 0.960327 \\
\hline 15 & 0.90782 & 0.90782 & 0.937673 & 0.949538 & 0.958883 & 0.953703 & 0.959986 & 0.959986 \\
\hline 16 & 0.906438 & 0.906438 & 0.936336 & 0.948217 & 0.957575 & 0.951171 & 0.958252 & 0.958252 \\
\hline 17 & 0.90439 & 0.90439 & 0.934353 & 0.94626 & 0.955637 & 0.94586 & 0.954851 & 0.954851 \\
\hline 18 & 0.903776 & 0.903776 & 0.93376 & 0.945674 & 0.955057 & 0.944021 & 0.953816 & 0.953816 \\
\hline 19 & 0.996497 & 0.996497 & 0.995304 & 0.995314 & 0.995164 & 0.995062 & 0.9953 & 0.9953 \\
\hline 20 & 0.992919 & 0.992919 & 0.980709 & 0.98076 & 0.979201 & 0.978159 & 0.980425 & 0.980425 \\
\hline 21 & 0.992215 & 0.992215 & 0.976632 & 0.976696 & 0.974713 & 0.973358 & 0.976262 & 0.976262 \\
\hline 22 & 0.991577 & 0.991577 & 0.975985 & 0.976049 & 0.970925 & 0.969038 & 0.972512 & 0.972512 \\
\hline 23 & 0.979308 & 0.979308 & 0.982512 & 0.982529 & 0.982969 & 0.983206 & 0.980834 & 0.980834 \\
\hline 24 & 0.972636 & 0.972636 & 0.975862 & 0.97588 & 0.976323 & 0.976561 & 0.970111 & 0.970111 \\
\hline 25 & 0.969311 & 0.969311 & 0.972548 & 0.972566 & 0.973011 & 0.973249 & 0.962766 & 0.962766 \\
\hline 26 & 0.947551 & 0.947551 & 0.961793 & 0.961856 & 0.963781 & 0.965171 & 0.970404 & 0.970404 \\
\hline 27 & 0.944987 & 0.944987 & 0.959269 & 0.959332 & 0.961262 & 0.963032 & 0.969108 & 0.969108 \\
\hline 28 & 0.933546 & 0.933546 & 0.948007 & 0.94807 & 0.950025 & 0.953851 & 0.963837 & 0.963837 \\
\hline 29 & 0.925327 & 0.925327 & 0.939916 & 0.93998 & 0.941952 & 0.947324 & 0.960257 & 0.960257 \\
\hline 30 & 0.921769 & 0.921769 & 0.936414 & 0.936479 & 0.938457 & 0.944496 & 0.957016 & 0.957016 \\
\hline 31 & 0.917607 & 0.917607 & 0.932318 & 0.932383 & 0.93437 & 0.942429 & 0.9538 & 0.9538 \\
\hline 32 & 0.916691 & 0.916691 & 0.931417 & 0.931482 & 0.933471 & 0.94226 & 0.953222 & 0.953222 \\
\hline 33 & 0.916407 & 0.916407 & 0.931138 & 0.931203 & 0.933193 & 0.942992 & 0.953405 & 0.953405 \\
\hline Min.V & 0.903776 & 0.903776 & 0.931138 & 0.931203 & 0.933193 & 0.94226 & 0.953222 & 0.953222 \\
\hline Bus & 18 & 18 & 33 & 33 & 33 & 32 & 32 & 32 \\
\hline $\begin{array}{c}\text { TPL } \\
(\mathrm{KW})\end{array}$ & 210.9824 & 210.9824 & 158.1731 & 152.2685 & 141.8479 & 135.6471 & 123.3572 & 123.3572 \\
\hline $\begin{array}{c}\text { TQL } \\
\text { (KVAR) }\end{array}$ & 143.0219 & 143.0219 & 112.6713 & 108.6812 & 102.2323 & 99.9035 & 88.33017 & 88.33017 \\
\hline ITER & 4 & 4 & 4 & 4 & 4 & 4 & 3 & 3 \\
\hline
\end{tabular}


Table 3. Voltage Profile (p.u.) for IEEE 69 Bus Distribution System

\begin{tabular}{|c|c|c|c|c|c|c|c|c|}
\hline \multirow{3}{*}{$\begin{array}{c}\text { Bus } \\
1 \\
\end{array}$} & \multicolumn{2}{|c|}{ Radial } & Loops-1 & Loops-2 & Loops-3 & Loops-4 & \multicolumn{2}{|c|}{ Loops-5 } \\
\hline & $\begin{array}{c}\text { Proposed } \\
\text { V (p.u) }\end{array}$ & $\begin{array}{c}\text { Ref }[6,7 \\
\text { and 16] } \\
\text { V(p.u) }\end{array}$ & \multicolumn{5}{|c|}{ Proposed V(p.u) } & $\begin{array}{c}\text { Ref [16] } \\
\text { V (p.u) }\end{array}$ \\
\hline & 1 & 1 & 1 & 1 & 1 & 1 & 1 & 1 \\
\hline 2 & 0.999955 & 0.999955 & 0.999955 & 0.999955 & 0.999955 & 0.999956 & 0.999956 & 0.999956 \\
\hline 3 & 0.99991 & 0.99991 & 0.99991 & 0.99991 & 0.99991 & 0.999912 & 0.999912 & 0.999912 \\
\hline 4 & 0.999783 & 0.999783 & 0.999814 & 0.999814 & 0.999815 & 0.999809 & 0.999817 & 0.999817 \\
\hline 5 & 0.998669 & 0.998669 & 0.999014 & 0.999015 & 0.999035 & 0.99938 & 0.999371 & 0.999371 \\
\hline 6 & 0.986488 & 0.986488 & 0.98999 & 0.989998 & 0.990234 & 0.994257 & 0.994044 & 0.994044 \\
\hline 7 & 0.973819 & 0.973819 & 0.980605 & 0.98062 & 0.981082 & 0.988935 & 0.98851 & 0.98851 \\
\hline 8 & 0.970797 & 0.970797 & 0.978377 & 0.978395 & 0.978911 & 0.98769 & 0.987214 & 0.987214 \\
\hline 9 & 0.96925 & 0.96925 & 0.977254 & 0.977272 & 0.977818 & 0.987091 & 0.986588 & 0.986588 \\
\hline 10 & 0.962528 & 0.962528 & 0.976528 & 0.976562 & 0.977543 & 0.984976 & 0.982188 & 0.982188 \\
\hline 11 & 0.961048 & 0.961048 & 0.976417 & 0.976454 & 0.977535 & 0.984546 & 0.981237 & 0.981237 \\
\hline 12 & 0.956792 & 0.956792 & 0.97223 & 0.972291 & 0.975746 & 0.982496 & 0.977607 & 0.977607 \\
\hline 13 & 0.952845 & 0.952845 & 0.968347 & 0.968444 & 0.975324 & 0.981684 & 0.974517 & 0.974517 \\
\hline 14 & 0.948934 & 0.948934 & 0.9645 & 0.967343 & 0.975981 & 0.982134 & 0.975375 & 0.975375 \\
\hline 15 & 0.94507 & 0.94507 & 0.9607 & 0.966325 & 0.976744 & 0.982687 & 0.976341 & 0.976341 \\
\hline 16 & 0.944353 & 0.944353 & 0.959994 & 0.966136 & 0.976239 & 0.982222 & 0.975524 & 0.975524 \\
\hline 17 & 0.943167 & 0.943167 & 0.958828 & 0.965953 & 0.975451 & 0.98151 & 0.974143 & 0.974143 \\
\hline 18 & 0.943155 & 0.943155 & 0.958817 & 0.965954 & 0.975444 & 0.981504 & 0.974129 & 0.974129 \\
\hline 19 & 529 & 0.942529 & 0.958201 & 0.966195 & 0.975153 & 276 & 0.973318 & 3318 \\
\hline 20 & 0.942127 & 0.942127 & 0.957805 & 0.96635 & 0.974965 & 0.981129 & 0.972798 & 0.972798 \\
\hline 21 & 0.941478 & 0.941478 & 0.957166 & 0.966606 & 0.974665 & 0.980895 & 0.971956 & 0.971956 \\
\hline 22 & 0.941468 & 0.941468 & 0.957157 & 0.966597 & 0.974656 & 0.980886 & 0.971886 & 0.971886 \\
\hline 23 & 0.941372 & 0.941372 & 0.957062 & 0.966502 & 0.974562 & 0.980793 & 0.971099 & 0.971099 \\
\hline 24 & 1161 & 0.941161 & 0.956855 & 0.966297 & 0.974359 & 0.980591 & 0.969384 & 9384 \\
\hline 25 & 0933 & 0.940933 & 0.956631 & 0.966076 & 0.974139 & 0.980372 & 0.965899 & 0.965899 \\
\hline 26 & 0.94084 & 0.94084 & 0.956539 & 0.965984 & 0.974048 & 0.980282 & 0.964462 & 0.964462 \\
\hline 27 & 0.940813 & 0.940813 & 0.956513 & 0.965958 & 0.974023 & 0.980257 & 0.963682 & 0.963682 \\
\hline 28 & 0.9999 & 0.9999 & 0.999901 & 0.999901 & 0.999901 & 0.999903 & 0.999903 & 0.999903 \\
\hline 29 & 0.999805 & 0.999805 & 0.999806 & 0.999806 & 9806 & 9808 & 99808 & 9808 \\
\hline 30 & 0.999645 & 0.999645 & 0.999645 & 0.999646 & 0.999646 & 647 & 0.999648 & 0.999648 \\
\hline 31 & 0.999617 & 0.999617 & 0.999617 & 0.999617 & 0.999617 & 0.999619 & 0.999619 & 0.999619 \\
\hline 32 & 0.999475 & 0.999475 & 0.999476 & 0.999476 & 0.999476 & 0.999477 & 0.999478 & 0.999478 \\
\hline 33 & & 0.999136 & & & & & 0.999138 & 0.999138 \\
\hline 34 & & 0.998691 & & 0.99 & & & 8694 & 3694 \\
\hline 35 & 0.998602 & 0.998602 & 0.998602 & 0.998602 & 0.998602 & 0.998604 & 0.998605 & 0.998605 \\
\hline 36 & 0.999891 & 0.999891 & 0.999805 & 0.999806 & 0.999802 & 0.999833 & 0.999815 & 0.999815 \\
\hline 37 & 0.999664 & 0.999664 & 0.998325 & 0.998327 & 0.998262 & 0.998727 & 0.998432 & 0.998432 \\
\hline 38 & 0.999454 & 0.999454 & 0.996841 & 0.996845 & 0.996709 & 0.997603 & 0.997025 & 0.997025 \\
\hline 39 & 0.999393 & 0.999393 & 0.996412 & 0.996417 & & 0.997279 & 0.996619 & 0.996619 \\
\hline 40 & 0.99939 & 0.99939 & 0.996387 & 0.996392 & 0.996234 & 0.997261 & 0.996596 & 0.996596 \\
\hline 41 & 0.998465 & 0.998465 & 0.98665 & 0.986671 & 0.986022 & 0.990019 & 0.987396 & 0.987396 \\
\hline 42 & 0.998078 & 0.998078 & 0.982511 & 0.982538 & 0.981681 & 0.986942 & 0.983485 & 0.983485 \\
\hline 43 & 0.998027 & 0.998027 & 0.981965 & 0.981992 & 0.981107 & 0.986536 & 0.982969 & 0.982969 \\
\hline 44 & 0.998016 & 0.998016 & 0.981954 & 0.981981 & 0.981049 & 0.986484 & 0.982886 & 0.982886 \\
\hline 45 & 0.997885 & 0.997885 & 0.981821 & 0.981848 & 0.980365 & 0.985867 & 0.981909 & 0.981909 \\
\hline 46 & 0.997884 & 0.997884 & 0.98182 & 0.981848 & 0.98036 & 0.985862 & 0.981902 & 0.981902 \\
\hline 47 & 0.999717 & 0.999717 & 0.999747 & 0.999747 & 0.999749 & 0.999652 & 0.999679 & 0.999679 \\
\hline 48 & 0.998063 & 0.998063 & 0.998093 & 0.998093 & 0.998095 & 0.995728 & 0.996239 & 0.996239 \\
\hline 49 & 0.992959 & 0.992959 & 0.992989 & 0.99299 & 0.992991 & 0.98292 & 0.985072 & 0.985072 \\
\hline 50 & 0.992236 & 0.992236 & 0.992266 & 0.992266 & 0.992268 & 0.980024 & 0.982638 & 0.982638 \\
\hline 51 & 0.97075 & 0.97075 & 0.97833 & 0.978348 & 0.978864 & 0.987643 & 0.987167 & 0.987167 \\
\hline 52 & 0.970737 & 0.970737 & 0.978318 & 0.978335 & 0.978851 & 0.987631 & 0.987155 & 0.987155 \\
\hline 53 & 0.965422 & 0.965422 & 0.973465 & 0.973483 & 0.974031 & 0.985505 & 0.985419 & 0.985419 \\
\hline 54 & 0.960967 & 0.960967 & 0.969054 & 0.969072 & 0.969623 & 0.983665 & 0.984065 & 0.984065 \\
\hline 55 & 0.954819 & 0.954819 & 0.962968 & 0.962986 & 0.963541 & 0.981174 & 0.982256 & 0.982256 \\
\hline 56 & 0.948814 & 0.948814 & 0.957023 & 0.957042 & 0.957601 & 0.978788 & 0.980544 & 0.980544 \\
\hline
\end{tabular}




\begin{tabular}{|c|c|c|c|c|c|c|c|c|}
\hline 57 & 0.917907 & 0.917907 & 0.926428 & 0.926447 & 0.927027 & 0.966026 & 0.97139 & 0.97139 \\
\hline 58 & 0.902706 & 0.902706 & 0.91138 & 0.911399 & 0.91199 & 0.959735 & 0.966878 & 0.966878 \\
\hline 59 & 0.896828 & 0.896828 & 0.905561 & 0.90558 & 0.906175 & 0.957297 & 0.96513 & 0.96513 \\
\hline 60 & 0.889923 & 0.889923 & 0.898725 & 0.898745 & 0.899344 & 0.950845 & 0.960428 & 0.960428 \\
\hline $\mathbf{6 1}$ & 0.879759 & 0.879759 & 0.888663 & 0.888683 & 0.889289 & 0.941348 & $\mathbf{0 . 9 5 3 4 7}$ & $\mathbf{0 . 9 5 3 4 7}$ \\
\hline 62 & 0.879361 & 0.879361 & 0.888269 & 0.888289 & 0.888895 & 0.940975 & 0.953567 & 0.953567 \\
\hline 63 & 0.878828 & 0.878828 & 0.887741 & 0.887761 & 0.888368 & 0.940477 & 0.953766 & 0.953766 \\
\hline 64 & 0.876214 & 0.876214 & 0.885154 & 0.885174 & 0.885783 & 0.938036 & 0.954741 & 0.954741 \\
\hline $\mathbf{6 5}$ & $\mathbf{0 . 8 7 5 4 2 4}$ & $\mathbf{0 . 8 7 5 4 2 4}$ & $\mathbf{0 . 8 8 4 3 7 2}$ & $\mathbf{0 . 8 8 4 3 9 2}$ & $\mathbf{0 . 8 8 5 0 0 1}$ & $\mathbf{0 . 9 3 7 2 9 8}$ & 0.958958 & 0.958958 \\
\hline 66 & 0.960972 & 0.960972 & 0.976342 & 0.976379 & 0.97746 & 0.984472 & 0.981162 & 0.981162 \\
\hline 67 & 0.960971 & 0.960971 & 0.976341 & 0.976378 & 0.977459 & 0.984471 & 0.981161 & 0.981161 \\
\hline 68 & 0.95635 & 0.95635 & 0.971795 & 0.971856 & 0.975312 & 0.982066 & 0.977174 & 0.977174 \\
\hline 69 & 0.956348 & 0.956348 & 0.971793 & 0.971855 & 0.97531 & 0.982064 & 0.977172 & 0.977172 \\
\hline \multicolumn{7}{|c|}{} \\
\hline \multicolumn{7}{|c|}{} \\
\hline Min.V & 0.875424 & 0.875424 & 0.884372 & 0.884392 & 0.885001 & 0.937298 & 0.95347 & 0.95347 \\
\hline Bus & 65 & 65 & 65 & 65 & 65 & 65 & 61 & 61 \\
\hline $\begin{array}{c}\text { TPL } \\
\text { (KW) }\end{array}$ & 317.907 & 317.907 & 276.6134 & 272.7975 & 266.4742 & 132.0892 & 111.881 & 111.881 \\
\hline $\begin{array}{c}\text { TQL } \\
\text { (KVAR) }\end{array}$ & 143.835 & 143.835 & 134.233 & 133.1886 & 130.4778 & 102.7655 & 88.15877 & 88.15877 \\
\hline ITER & 5 & 5 & 5 & 5 & 5 & 4 & 3 & 3 \\
\hline
\end{tabular}

Table 4. Voltage Profile (p.u.) for 33 Bus Mesh Network with Load Models, Load Growth, and Increase in R \& X

\begin{tabular}{|c|c|c|c|c|c|c|c|c|}
\hline & Ref [16] & \multicolumn{7}{|c|}{ Proposed method } \\
\hline Bus No & $\begin{array}{c}\mathrm{CP}-\mathrm{V} \\
\text { (p.u) }\end{array}$ & $\begin{array}{c}\text { CP - V } \\
\text { (p.u) }\end{array}$ & $\begin{array}{c}\text { CI - V } \\
\text { (p.u) }\end{array}$ & $\begin{array}{c}\mathrm{CZ}-\mathrm{V} \\
\text { (p.u) }\end{array}$ & $\begin{array}{c}\text { ZIP - V } \\
\text { (p.u) }\end{array}$ & $\begin{array}{c}\text { LG - V } \\
\text { (p.u) }\end{array}$ & $\begin{array}{c}10 \% \text { inc. } \\
\text { in } \mathrm{R}-\mathrm{V} \\
\text { (p.u) }\end{array}$ & $\begin{array}{c}10 \% \text { inc. } \\
\text { in } \mathrm{X}-\mathrm{V} \\
\text { (p.u) }\end{array}$ \\
\hline 1 & 1 & 1 & 1 & 1 & 1 & 1 & 1 & 1 \\
\hline 2 & 0.997092 & 0.997092 & 0.997188 & 0.997275 & 0.997168 & 0.99586 & 0.996863 & 0.997019 \\
\hline 3 & 0.986332 & 0.986332 & 0.9868 & 0.98722 & 0.986704 & 0.980532 & 0.985285 & 0.985959 \\
\hline 4 & 0.982711 & 0.982711 & 0.983303 & 0.983834 & 0.983182 & 0.975374 & 0.981393 & 0.982233 \\
\hline 5 & 0.979329 & 0.979329 & 0.980044 & 0.980685 & 0.979898 & 0.970553 & 0.977759 & 0.978752 \\
\hline 6 & 0.971425 & 0.971425 & 0.972435 & 0.97334 & 0.972228 & 0.959275 & 0.969346 & 0.97053 \\
\hline 7 & 0.970504 & 0.970504 & 0.971544 & 0.972477 & 0.971331 & 0.957962 & 0.968388 & 0.969547 \\
\hline 8 & 0.96825 & 0.96825 & 0.969379 & 0.97039 & 0.969148 & 0.954746 & 0.965989 & 0.967206 \\
\hline 9 & 0.965091 & 0.965091 & 0.966351 & 0.967479 & 0.966093 & 0.950229 & 0.962599 & 0.963945 \\
\hline 10 & 0.964721 & 0.964721 & 0.965995 & 0.967136 & 0.965734 & 0.949702 & 0.962213 & 0.963554 \\
\hline 11 & 0.964732 & 0.964732 & 0.966006 & 0.967147 & 0.965745 & 0.949718 & 0.962228 & 0.963562 \\
\hline 12 & 0.964886 & 0.964886 & 0.966155 & 0.967292 & 0.965896 & 0.949937 & 0.962402 & 0.963713 \\
\hline 13 & 0.961521 & 0.961521 & 0.962932 & 0.964195 & 0.962643 & 0.945124 & 0.958788 & 0.960242 \\
\hline 14 & 0.960327 & 0.960327 & 0.96179 & 0.9631 & 0.96149 & 0.943416 & 0.957521 & 0.958996 \\
\hline 15 & 0.959986 & 0.959986 & 0.961467 & 0.962792 & 0.961164 & 0.942927 & 0.957152 & 0.958647 \\
\hline 16 & 0.958252 & 0.958252 & 0.959814 & 0.96121 & 0.959494 & 0.940441 & 0.955288 & 0.956859 \\
\hline 17 & 0.954851 & 0.954851 & 0.95657 & 0.958106 & 0.956218 & 0.935569 & 0.951698 & 0.95329 \\
\hline 18 & 0.953816 & 0.953816 & 0.955585 & 0.957165 & 0.955222 & 0.934084 & 0.950595 & 0.952213 \\
\hline 19 & 0.9953 & 0.9953 & 0.995455 & 0.995594 & 0.995424 & 0.993309 & 0.994944 & 0.995168 \\
\hline 20 & 0.980425 & 0.980425 & 0.9811 & 0.981705 & 0.980962 & 0.972112 & 0.97899 & 0.979823 \\
\hline 21 & 0.976262 & 0.976262 & 0.977089 & 0.97783 & 0.97692 & 0.966176 & 0.974553 & 0.975501 \\
\hline 22 & 0.972512 & 0.972512 & 0.973479 & 0.974346 & 0.973281 & 0.960826 & 0.970566 & 0.971598 \\
\hline 23 & 0.980834 & 0.980834 & 0.981502 & 0.9821 & 0.981365 & 0.972694 & 0.979399 & 0.980276 \\
\hline 24 & 0.970111 & 0.970111 & 0.97118 & 0.972138 & 0.970961 & 0.957395 & 0.967956 & 0.969153 \\
\hline 25 & 0.962766 & 0.962766 & 0.964137 & 0.965362 & 0.963856 & 0.9469 & 0.960143 & 0.961508 \\
\hline 26 & 0.970404 & 0.970404 & 0.971455 & 0.972397 & 0.97124 & 0.957817 & 0.968251 & 0.969477 \\
\hline 27 & 0.969108 & 0.969108 & 0.970213 & 0.971202 & 0.969987 & 0.955966 & 0.966863 & 0.968138 \\
\hline 28 & 0.963837 & 0.963837 & 0.965164 & 0.966351 & 0.964892 & 0.948429 & 0.961291 & 0.962614 \\
\hline 29 & 0.960257 & 0.960257 & 0.961738 & 0.963062 & 0.961435 & 0.943308 & 0.957515 & 0.958855 \\
\hline 30 & 0.957016 & 0.957016 & 0.958641 & 0.960091 & 0.958307 & 0.93867 & 0.954069 & 0.955479 \\
\hline 31 & 0.9538 & 0.9538 & 0.955571 & 0.957153 & 0.955208 & 0.934061 & 0.950605 & 0.95217 \\
\hline 32 & 0.953222 & 0.953222 & 0.95502 & 0.956625 & 0.954651 & 0.933233 & 0.949981 & 0.951577 \\
\hline 33 & 0.953405 & 0.953405 & 0.955195 & 0.956792 & 0.954827 & 0.933495 & 0.950166 & 0.951777 \\
\hline
\end{tabular}




\begin{tabular}{|c|c|c|c|c|c|c|c|c|}
\hline & & & & & & & & \\
\hline $\begin{array}{c}\text { MinV } \\
\text { (p.u) }\end{array}$ & 0.953222 & 0.953222 & 0.95502 & 0.956625 & 0.954651 & 0.933233 & 0.949981 & 0.951577 \\
\hline bus & 32 & 32 & 32 & 32 & 32 & 32 & 32 & 32 \\
\hline $\begin{array}{c}\text { TPL } \\
\text { (kW) }\end{array}$ & 123.3572 & 123.3572 & 114.4797 & 106.8243 & 116.2727 & 250.8541 & 136.3236 & 123.7742 \\
\hline $\begin{array}{c}\text { TQL } \\
\text { (kW) }\end{array}$ & 88.33017 & 88.33017 & 81.91244 & 76.38172 & 83.2088 & 179.683 & 88.90792 & 97.31244 \\
\hline ITER & 3 & 3 & 2 & 3 & 3 & 4 & 3 & 3 \\
\hline $\begin{array}{c}\text { TIME } \\
\text { (sec) }\end{array}$ & 0.025359 & 0.018051 & 0.019686 & 0.019847 & 0.020221 & 0.018524 & 0.018567 & 0.018575 \\
\hline
\end{tabular}

Table 5: Voltage Profile (p.u.) for 69 Bus Mesh Network with Load Models, Load Growth, and Increase in $R$ \& X

\begin{tabular}{|c|c|c|c|c|c|c|c|c|}
\hline & $\operatorname{Ref}[16]$ & \multicolumn{7}{|c|}{ Proposed method } \\
\hline Bus No & $\begin{array}{c}\mathrm{CP}-\mathrm{V} \\
(\mathrm{p} . \mathrm{u})\end{array}$ & $\begin{array}{c}\text { CP - V } \\
\text { (p.u) }\end{array}$ & $\begin{array}{c}\text { CI - V } \\
\text { (p.u) }\end{array}$ & $\begin{array}{c}C Z-V \\
(p . u)\end{array}$ & $\begin{array}{c}\text { ZIP - V } \\
\quad(\text { p.u })\end{array}$ & $\begin{array}{c}\mathrm{LG}-\mathrm{V} \\
(\mathrm{p} . \mathrm{u})\end{array}$ & $\begin{array}{c}10 \% \text { inc. } \\
\text { in } \mathrm{R}-\mathrm{V} \\
\text { (p.u) }\end{array}$ & $\begin{array}{c}10 \% \text { inc. } \\
\text { in } X-V \\
\text { (p.u) }\end{array}$ \\
\hline 1 & 1 & 1 & 1 & 1 & 1 & 1 & 1 & 1 \\
\hline 2 & 0.999956 & 0.999956 & 0.999957 & 0.999959 & 0.999957 & 0.999938 & 0.999955 & 0.999953 \\
\hline 3 & 0.999912 & 0.999912 & 0.999915 & 0.999917 & 0.999914 & 0.999875 & 0.999909 & 0.999907 \\
\hline 4 & 0.999817 & 0.999817 & 0.999822 & 0.999827 & 0.999821 & 0.99974 & 0.99981 & 0.999805 \\
\hline 5 & 0.999371 & 0.999371 & 0.999391 & 0.999408 & 0.999387 & 0.999105 & 0.999342 & 0.999334 \\
\hline 6 & 0.994044 & 0.994044 & 0.994235 & 0.994406 & 0.994196 & 0.991525 & 0.99368 & 0.993792 \\
\hline 7 & 0.98851 & 0.98851 & 0.988879 & 0.989209 & 0.988804 & 0.983648 & 0.987796 & 0.988034 \\
\hline 8 & 0.987214 & 0.987214 & 0.987626 & 0.987994 & 0.987541 & 0.981803 & 0.986419 & 0.986685 \\
\hline 9 & 0.986588 & 0.986588 & 0.987022 & 0.98741 & 0.986933 & 0.980911 & 0.985755 & 0.986033 \\
\hline 10 & 0.982188 & 0.982188 & 0.982754 & 0.983261 & 0.982639 & 0.974657 & 0.981084 & 0.981454 \\
\hline 11 & 0.981237 & 0.981237 & 0.981832 & 0.982365 & 0.98171 & 0.973304 & 0.980075 & 0.980463 \\
\hline 12 & 0.977607 & 0.977607 & 0.978327 & 0.978971 & 0.978179 & 0.968132 & 0.976158 & 0.976743 \\
\hline 13 & 0.974517 & 0.974517 & 0.975369 & 0.976131 & 0.975194 & 0.963713 & 0.97283 & 0.973566 \\
\hline 14 & 0.975375 & 0.975375 & 0.976194 & 0.976927 & 0.976026 & 0.964938 & 0.973777 & 0.974424 \\
\hline 15 & 0.976341 & 0.976341 & 0.977125 & 0.977826 & 0.976965 & 0.966317 & 0.974841 & 0.975393 \\
\hline 16 & 0.975524 & 0.975524 & 0.976337 & 0.977065 & 0.976171 & 0.965152 & 0.973959 & 0.974556 \\
\hline 17 & 0.974143 & 0.974143 & 0.975009 & 0.975783 & 0.974832 & 0.963181 & 0.972469 & 0.973141 \\
\hline 18 & 0.974129 & 0.974129 & 0.974995 & 0.975769 & 0.974818 & 0.96316 & 0.972453 & 0.973126 \\
\hline 19 & 0.973318 & 0.973318 & 0.97422 & 0.975026 & 0.974035 & 0.962001 & 0.971581 & 0.972292 \\
\hline 20 & 0.972798 & 0.972798 & 0.973722 & 0.974548 & 0.973533 & 0.961255 & 0.971021 & 0.971756 \\
\hline 21 & 0.971956 & 0.971956 & 0.972918 & 0.973776 & 0.972721 & 0.960051 & 0.970116 & 0.97089 \\
\hline 22 & 0.971886 & 0.971886 & 0.972851 & 0.973712 & 0.972653 & 0.959951 & 0.97004 & 0.970818 \\
\hline 23 & 0.971099 & 0.971099 & 0.9721 & 0.972994 & 0.971895 & 0.958822 & 0.96919 & 0.97001 \\
\hline 24 & 0.969384 & 0.969384 & 0.970466 & 0.97143 & 0.970244 & 0.956365 & 0.96734 & 0.968251 \\
\hline 25 & 0.965899 & 0.965899 & 0.967146 & 0.968256 & 0.96689 & 0.951369 & 0.963581 & 0.964673 \\
\hline 26 & 0.964462 & 0.964462 & 0.965777 & 0.966947 & 0.965507 & 0.949308 & 0.96203 & 0.963197 \\
\hline 27 & 0.963682 & 0.963682 & 0.965034 & 0.966238 & 0.964756 & 0.948189 & 0.961189 & 0.962396 \\
\hline 28 & 0.999903 & 0.999903 & 0.999906 & 0.999908 & 0.999905 & 0.999863 & 0.9999 & 0.999897 \\
\hline 29 & 0.999808 & 0.999808 & 0.999811 & 0.999813 & 0.99981 & 0.999729 & 0.999801 & 0.999796 \\
\hline 30 & 0.999648 & 0.999648 & 0.999651 & 0.999653 & 0.99965 & 0.999504 & 0.999628 & 0.999632 \\
\hline 31 & 0.999619 & 0.999619 & 0.999622 & 0.999625 & 0.999622 & 0.999464 & 0.999597 & 0.999604 \\
\hline 32 & 0.999478 & 0.999478 & 0.999481 & 0.999484 & 0.99948 & 0.999266 & 0.999444 & 0.999459 \\
\hline 33 & 0.999138 & 0.999138 & 0.999142 & 0.999145 & 0.999141 & 0.998789 & 0.999077 & 0.999113 \\
\hline 34 & 0.998694 & 0.998694 & 0.998698 & 0.998702 & 0.998697 & 0.998166 & 0.998596 & 0.99866 \\
\hline 35 & 0.998605 & 0.998605 & 0.998609 & 0.998613 & 0.998608 & 0.99804 & 0.9985 & 0.998569 \\
\hline 36 & 0.999815 & 0.999815 & 0.99982 & 0.999825 & 0.999819 & 0.999736 & 0.999807 & 0.999803 \\
\hline 37 & 0.998432 & 0.998432 & 0.998479 & 0.998521 & 0.99847 & 0.997771 & 0.998368 & 0.998336 \\
\hline 38 & 0.997025 & 0.997025 & 0.997116 & 0.997197 & 0.997097 & 0.99577 & 0.996875 & 0.99687 \\
\hline 39 & 0.996619 & 0.996619 & 0.996722 & 0.996814 & 0.996701 & 0.995193 & 0.996444 & 0.996447 \\
\hline 40 & 0.996596 & 0.996596 & 0.9967 & 0.996792 & 0.996678 & 0.99516 & 0.996419 & 0.996423 \\
\hline 41 & 0.987396 & 0.987396 & 0.987797 & 0.988156 & 0.987715 & 0.982066 & 0.98665 & 0.986841 \\
\hline 42 & 0.983485 & 0.983485 & 0.984013 & 0.984486 & 0.983905 & 0.976501 & 0.982498 & 0.982768 \\
\hline 43 & 0.982969 & 0.982969 & 0.983513 & 0.984001 & 0.983402 & 0.975766 & 0.981949 & 0.982231 \\
\hline
\end{tabular}




\begin{tabular}{|c|c|c|c|c|c|c|c|c|}
\hline 44 & 0.982886 & 0.982886 & 0.983434 & 0.983924 & 0.983322 & 0.975649 & 0.981862 & 0.982144 \\
\hline 45 & 0.981909 & 0.981909 & 0.98249 & 0.98301 & 0.982371 & 0.974258 & 0.980833 & 0.981118 \\
\hline 46 & 0.981902 & 0.981902 & 0.982483 & 0.983003 & 0.982364 & 0.974247 & 0.980825 & 0.98111 \\
\hline 47 & 0.999679 & 0.999679 & 0.999688 & 0.999697 & 0.999686 & 0.999543 & 0.999666 & 0.999658 \\
\hline 48 & 0.996239 & 0.996239 & 0.996351 & 0.996451 & 0.996328 & 0.994652 & 0.996096 & 0.995996 \\
\hline 49 & 0.985072 & 0.985072 & 0.985528 & 0.985936 & 0.985435 & 0.978776 & 0.9845 & 0.984111 \\
\hline 50 & 0.982638 & 0.982638 & 0.983181 & 0.983666 & 0.983069 & 0.975311 & 0.981971 & 0.981522 \\
\hline 51 & 0.987167 & 0.987167 & 0.98758 & 0.987949 & 0.987495 & 0.981738 & 0.986369 & 0.986637 \\
\hline 52 & 0.987155 & 0.987155 & 0.987568 & 0.987936 & 0.987483 & 0.98172 & 0.986356 & 0.986625 \\
\hline 53 & 0.985419 & 0.985419 & 0.9859 & 0.986329 & 0.985801 & 0.979241 & 0.984511 & 0.984816 \\
\hline 54 & 0.984065 & 0.984065 & 0.984601 & 0.985079 & 0.984491 & 0.977307 & 0.98307 & 0.983408 \\
\hline 55 & 0.982256 & 0.982256 & 0.982868 & 0.983413 & 0.982742 & 0.974721 & 0.981146 & 0.981524 \\
\hline 56 & 0.980544 & 0.980544 & 0.981229 & 0.981839 & 0.981088 & 0.972272 & 0.979326 & 0.97974 \\
\hline 57 & 0.97139 & 0.97139 & 0.972464 & 0.973418 & 0.972243 & 0.959178 & 0.969561 & 0.970242 \\
\hline 58 & 0.966878 & 0.966878 & 0.968144 & 0.969268 & 0.967884 & 0.952725 & 0.964748 & 0.96556 \\
\hline 59 & 0.96513 & 0.96513 & 0.96647 & 0.96766 & 0.966194 & 0.950224 & 0.962882 & 0.963746 \\
\hline 60 & 0.960428 & 0.960428 & 0.961982 & 0.963359 & 0.961662 & 0.94349 & 0.957765 & 0.958964 \\
\hline 61 & $\mathbf{0 . 9 5 3 4 7}$ & $\mathbf{0 . 9 5 3 4 7}$ & $\mathbf{0 . 9 5 5 3 3 8}$ & 0.956993 & 0.954953 & 0.933528 & 0.950259 & 0.951821 \\
\hline 62 & 0.953567 & 0.953567 & 0.955429 & 0.957079 & 0.955045 & 0.933668 & 0.950361 & 0.951923 \\
\hline 63 & 0.953766 & 0.953766 & 0.955616 & 0.957256 & 0.955235 & 0.933955 & 0.950572 & 0.952131 \\
\hline 64 & 0.954741 & 0.954741 & 0.956533 & 0.958123 & 0.956164 & 0.935361 & 0.951606 & 0.953152 \\
\hline 65 & 0.958958 & 0.958958 & 0.96054 & 0.961945 & 0.960215 & 0.941414 & 0.956123 & 0.957515 \\
\hline 66 & 0.981162 & 0.981162 & 0.981759 & 0.982293 & 0.981637 & 0.973199 & 0.979995 & 0.980387 \\
\hline 67 & 0.981161 & 0.981161 & 0.981758 & 0.982292 & 0.981636 & 0.973198 & 0.979994 & 0.980386 \\
\hline 68 & 0.977174 & 0.977174 & 0.977904 & 0.978558 & 0.977754 & 0.967519 & 0.975689 & 0.976301 \\
\hline 69 & 0.977172 & 0.977172 & 0.977902 & 0.978556 & 0.977753 & 0.967517 & 0.975688 & 0.9763 \\
\hline $\begin{array}{c}\text { MinV } \\
\text { (p.u) }\end{array}$ & 0.95347 & 0.95347 & 0.955338 & 0.956993 & 0.954953 & 0.933528 & 0.950259 & 0.951821 \\
\hline Bus & 61 & 61 & 61 & 61 & 61 & 61 & 61 & 61 \\
\hline $\begin{array}{l}\text { TPL } \\
(\mathrm{kW})\end{array}$ & 111.881 & 111.881 & 103.3997 & 96.16002 & 105.1167 & 227.9442 & 123.0031 & 112.9425 \\
\hline $\begin{array}{c}\text { TQL } \\
\text { (kVAr) }\end{array}$ & 88.15877 & 88.15877 & 82.02806 & 76.76225 & 83.26846 & 179.0664 & 88.99986 & 96.75632 \\
\hline ITER & 3 & 3 & 2 & 3 & 3 & 4 & 3 & 3 \\
\hline $\begin{array}{l}\text { TIME } \\
(\mathrm{sec})\end{array}$ & 0.028915 & 0.018837 & 0.020463 & 0.020676 & 0.021195 & 0.019371 & 0.019326 & 0.019362 \\
\hline
\end{tabular}

Table 6: Results for Mesh Distribution Systems Under Different Loading Conditions

\begin{tabular}{|c|c|c|c|c|c|}
\hline \multicolumn{7}{|c|}{33 bus system } \\
\hline Loading & Total Load & TPL & TQL & MinV & ITER \\
\hline $50 \%$ & $1857.5+\mathrm{j} 1150$ & 29.66855 & 21.23623 & 0.97708 & 3 \\
\hline $100 \%$ & $3715+\mathrm{j} 2300$ & 123.3572 & 88.33017 & 0.953222 & 3 \\
\hline $150 \%$ & $5572.5+\mathrm{j} 3450$ & 289.3102 & 207.2453 & 0.928281 & 4 \\
\hline $200 \%$ & $7430+\mathrm{j} 4600$ & 537.6557 & 385.3144 & 0.90211 & 4 \\
\hline $250 \%$ & $9287.5+\mathrm{j} 5750$ & 881.4571 & 632.004 & 0.874491 & 5 \\
\hline \multicolumn{7}{|c|}{69 bus system } \\
\hline $50 \%$ & $1901.295+\mathrm{j} 1348.8$ & 26.856 & 21.2359 & 0.97723 & 3 \\
\hline $100 \%$ & $3802.59+\mathrm{j} 2697.6$ & 111.881 & 88.1587 & 0.95347 & 3 \\
\hline $150 \%$ & $5703.885+\mathrm{j} 4046.4$ & 263.0181 & 206.4613 & 0.928582 & 4 \\
\hline $200 \%$ & $7605.18+\mathrm{j} 5395.2$ & 490.189 & 383.194 & 0.90239 & 4 \\
\hline $250 \%$ & $9506.475+\mathrm{j} 6744$ & 806.5055 & 627.594 & 0.874645 & 5 \\
\hline
\end{tabular}




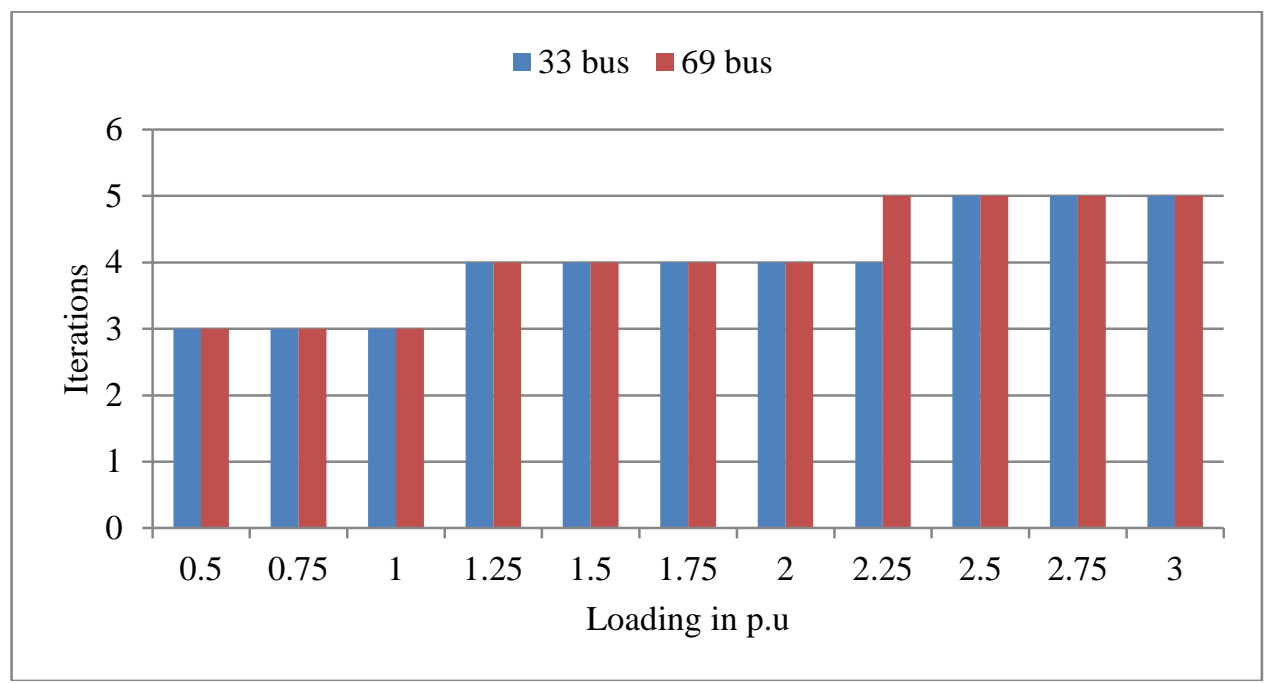

Figure 4. Variation of the Iteration Number with Different Loading Conditions

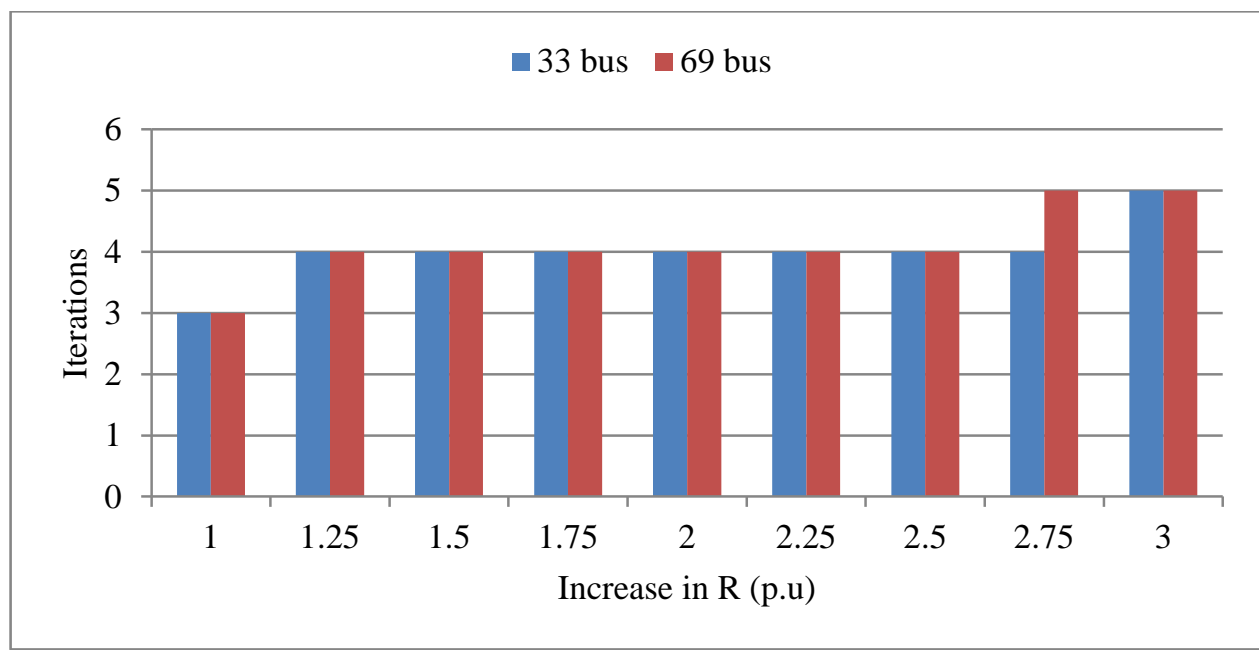

Figure 5. Variation of the Iteration Number with Increase in $\mathbf{R}$ Values

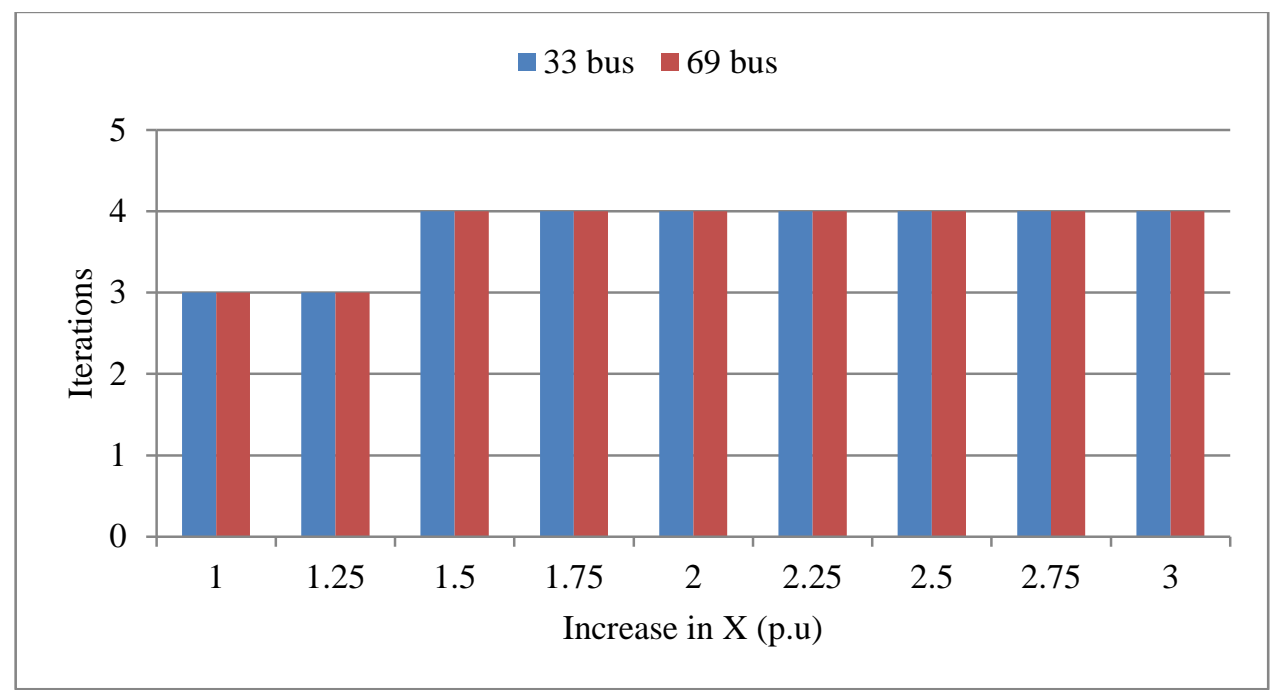

Figure 6. Variation of the Iteration Number with Increase in $X$ Values 


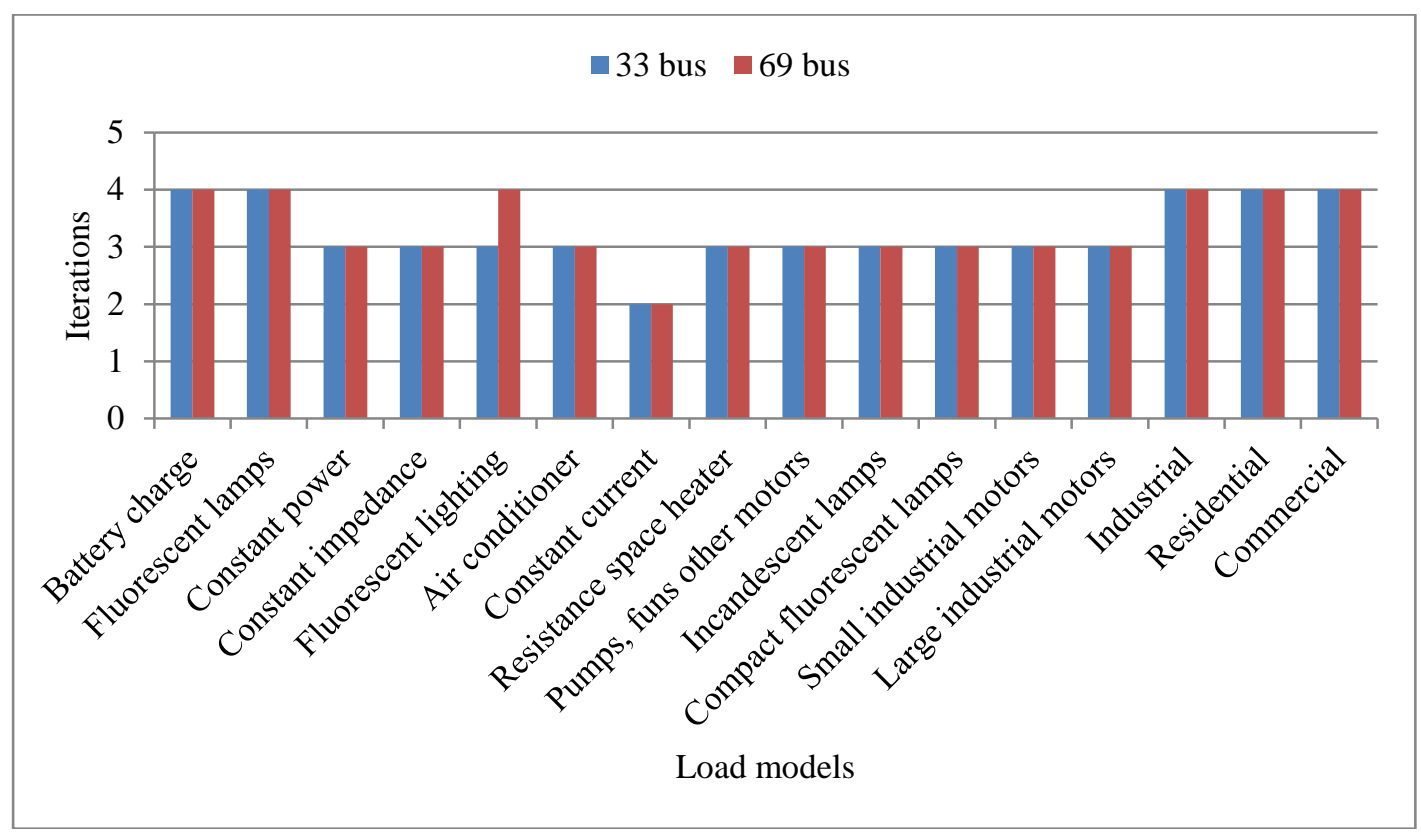

Figure 7. Variation of the Iteration Number with Different Static Load Models

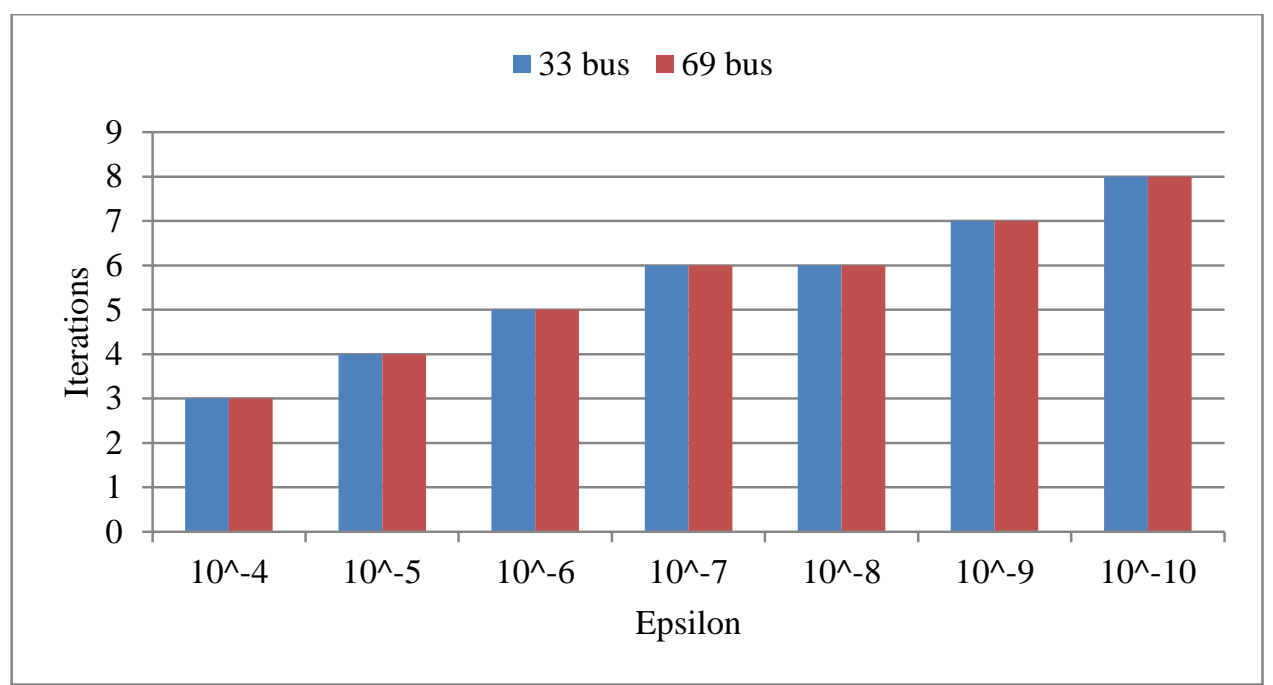

Figure 8. Variation of the Iteration Number with Different Tolerance Values

\section{Conclusions}

In this paper, an efficient and simple network topology based method for distribution power flow analysis of radial and mesh systems is proposed. The proposed method is compared with existing methods and it has been shown to be superior in the number of iterations, computationally efficient, and the robustness of convergence while the solution accuracy is well maintained. The results obtained with the proposed load flow approach are in close agreement with the all existing methods. The proposed load flow method has been evaluated on two IEEE benchmark distribution systems under different loading conditions, different $\mathrm{R} / \mathrm{X}$ ratio, different static load models and considering load growth also to observe the robustness of the method to provide solution of load flows. The results show that the proposed load flow method is simple and has fast convergence ability. 


\section{Acknowledgement}

This part of the work has been carried out under the project SR/S3/EECE/0035/2012 sponsored by Department of Science and Technology, GOI, New Delhi. The author acknowledges DST, GOI, New Delhi.

\section{References}

[1] S. B, Alsac O. "Fast decoupled load flow", IEEE Transactions on Power Apparatus and Systems, (1974), PAS-93, vol. 3, pp. 859-869

[2] A ASallam, O P. Malik, "Electrical Distribution Systems", John Wiley and Sons, (2011).

[3] W H Kersting, "Distribution System Modeling and Analysis", Boca Raton, FL: CRC Press, (2002).

[4] D Das, D P Kothari, A. Kalam, "Simple and efficient method for load flow solution of radial distribution networks", International Journal of Electrical Power \& Energy Systems, , vol. 17, no. 5, (1995), pp. 335-346

[5] M H. Haque, "Load flow solution of distribution systems with voltage dependent load models", Electric Power Systems Research, vol. 36, no. 3, (1996), pp. 151-156.

[6] S. Ghosh, D. Das, "Method for load-flow solution of radial distribution networks", IEE ProceedingsGeneration, Transmission and Distribution, vol. 146, no. 6, (1999), pp. 641-648.

[7] P. Aravindhabab, S Ganapathy, K R. Nayar, "A novel technique for the analysis of radial distribution systems", International Journal of Electrical Power \& Energy Systems, vol. 23, no. 3, (2001), pp. $167-171$.

[8] U. Eminoglu, M H Hocaoglu, "A new power flow method for radial distribution systems including voltage dependent load models", Electric Power Systems Research, vol. 76, no. 2, , (2005), pp.106-114.

[9] D. Shirmohammadi, H W Hong, A. Semlyen, G X Luo, "A compensation-based power-flow method for weakly meshed distribution and transmission networks", IEEE Transactions on Power Systems, vol. 3, no. 2, (1988), pp. 753-762.

[10] G X Luo, A. Semlyen A, "Efficient load flow for large weakly meshed networks", IEEE Transactions on Power Systems, vol.5, no. 4, (1990), pp. 1309-1316.

[11] M H Haque, "A general load flow method for distribution systems", Electric Power Systems Research, vol. 54, no. 1, (2000), pp. 47-54.

[12] A Losi, M. Russo, "Object oriented load flow for radial and weakly meshed distribution networks", IEEE Transactions on Power Systems, vol. 18, no. 4, (2003), pp. 1265-1275.

[13] S. Sivanagaraju, J V Rao, M. Giridhar, "A loop based load flow method for weakly meshed distribution network", APRN Journal of Engineering and Applied Sciences, vol. 3, no. 4, (2008), pp.55-59.

[14] D. Rajieic, R. Taleski, “Two novel methods for radial and weakly meshed network analysis”, Electric Power Systems Research, vol. 48, no. 2, (1998), pp. 79-87.

[15] G. Chang, S Y Chu, M F Hsu, C S Chuang, H L Wang, "An efficient power flow algorithm for weakly meshed distribution system”, Electric Power Systems Research, vol. 84, no. 1, (2012), pp. 90-99.

[16] J H Teng, "A direct approach for distribution system load flow solutions", IEEE Transactions on Power Delivery, vol. 18, no. 3, (2003), pp. 882-887.

[17] P R Bijwe, G K V Raju, "Fuzzy distribution power flow for weakly meshed systems", IEEE Transactions on Power Systems, vol. 21, no. 4, (2006), pp. 1645- 1652.

[18] C Dharmasa, Radhakrishna, H S Jain, P P Reddy, "load flow method for radial and weakly-meshed networks: concept of duality", In Proceedings of IEEE Power Systems Conference and Exposition, Seattle, WA, (2009), pp. 1-9.

[19] W M Lin, J H Teng, "Phase-decoupled load flow method for radial and weakly-meshed distribution networks", IEE Proceedings- Generation, Transmission and Distribution, vol.143, no. 1, (1996), pp. 39-42

[20] G J Chen , K K Li, T S Chung G Q Tang, "An efficient two-stage load flow method for meshed distribution networks", In Proceedings of IEEE 5th International Conference on Advances in Power System Control, Operation and Management, Hong Kong, China, (2000), pp. 537-542.

[21] G W Stagg, A H El-Abiad, "Computer Methods in Power System Analysis”, New York: McGraw Hill, (1968).

[22] M A Kashem, V. Ganapathy, G B Jasmon, M I Buhari, "A novel method for loss minimization in distribution networks", In Proceedings of IEEE International Conference on Electric Utility Deregulation and Restructuring and Power Technologies, London, UK, (2000), pp. 251-256.

[23] S Sivanagaraju, N Visali, V. Sankar, T Ramana, "Enhancing voltage stability of radial distribution systems by network reconfiguration", Electric Power Components and Systems, vol. 33, no. 5, (2005), pp. 539-550.

[24] The MATLAB by Mathworks Corporation, SIMULINK toolbox of MATLAB version 7.0.4, (2007). 
International Journal of Grid and Distributed Computing Vol. 9, No. 2 (2016) 